\title{
ANÁLISE ECONOMÉTRICA DA DEMANDA BRASILEIRA DE IMPORTAÇÃO DE BORRACHA NATURAL, DE 1964 A $2005^{1}$
}

\author{
Naisy Silva Soares², Márcio Lopes da Silva ${ }^{3}$, Sebastião Renato Valverde ${ }^{3}$, Ricardo Ribeiro Alves ${ }^{2}$ e \\ Fabiano Lourenço dos Santos ${ }^{2}$
}

\begin{abstract}
RESUMO - Este trabalho teve por objetivos especificar e estimar a demanda brasileira de importação de borracha natural, no período de 1964 a 2005. As variáveis explicativas do modelo de demanda de importação foram: preço de importação da borracha natural, PIB per capita, taxa de câmbio, taxa de juros, quantidade de borracha natural produzida internamente e tendência. As estimativas obtidas utilizando o modelo de ajustamento parcial confirmaram que as variáveis explicativas afetam, significativamente, a demanda brasileira de importação de borracha natural. Os resultados apontaram que a demanda brasileira de importação de borracha natural é inelástica com relação ao preço de importação e à renda; é pouco sensível a variações no preço de importação, à taxa de câmbio, à renda e à taxa de juros, mas é sensível às variações na quantidade de borracha natural produzida internamente, no curto e longo prazos; e a borracha natural é um bem normal.
\end{abstract}

Palavra-chave: Borracha natural, demanda de importação e produto florestal.

\section{ECONOMETRIC ANALYSIS OF BRAZILIAN IMPORT DEMAND FOR NATURAL RUBBER DURING 1964-2005}

\begin{abstract}
This work aimed to specify and estimate the Brazilian import demand for natural rubber from 1964 to 2005. The variables applied to explain import demand were: natural rubber import price, GNP per capita, exchange nominal rate (R\$/US\$), "overnight" interest rate, natural rubber domestic production and trend. The estimates showed that the variables significantly affected the Brazilian import demand for natural rubber. The results indicated that the Brazilian import demand for natural rubber is inelastic in relation to import price and income; little sensitive to variations in import price, exchange nominal rate (R\$/US\$), income and "overnight" interest rate but it is sensitive to domestic rubber production variations, in the short and long runs; and that natural rubber is a regular commodity.
\end{abstract}

Keywords: Natural rubber, importation demand and forest product.

\section{INTRODUÇÃ̃o}

A principal matéria-prima para a produção da borracha natural é o látex extraído da seringueira. Esta planta pertence ao gênero Hevea, com 11 espécies, das quais a Hevea brasiliensis é a única plantada e explorada comercialmente por ser a mais produtiva e possuir látex de qualidade superior às das demais. Como o próprio nome indica, a Hevea brasiliensis é originária do Brasil, mais especificamente da região amazônica. A borracha produzida a partir dessa árvore é utilizada nos setores hospitalar/farmacêutico, brinquedos, calçados, construção civil, maquinário agrícola e industrial e de autopeças. A planta foi descoberta em meados do século XVIII, e atualmente, é a principal fonte de borracha natural do mundo (PEREIRA et al., 2000; BEGA, 2004; BORRACHA NATURAL, 2007). Embora a borracha sintética tenha quase a mesma

\footnotetext{
${ }^{1}$ Recebido em 30.03.2007 e aceito para publicação em 22.08.2008.

${ }^{2}$ Programa de Pós-Graduação em Ciência Florestal da Universidade Federal de Viçosa (UFV). E-mail: <naisysilva@ yahoo.com.br>.

${ }_{3}^{3}$ Departamento de Engenharia Florestal da UFV. E-mail: <marlosil@ufv.br> e < valverde@ufv.br>.
} 
composição química da borracha natural, suas propriedades físicas são inferiores na produção de muitos produtos. Esse fato reforça a importância da borracha natural no mundo, limitando o grau de substituição pela borracha sintética (MERA, 1977; SANTOS e MOTHÉ, 2007). Outra questão importante é o fato de que o consumo de borracha sintética nos últimos anos vem perdendo mercado, tendência esta que é permanente, uma vez que esse produto é obtido do petróleo que vem apresentando aumento de preços. Tal fato tende a piorar, pois as reservas de petróleo são fontes não renováveis, e os países produtores estão constantemente em conflitos. Além disso, a indústria de borracha sintética vem sofrendo com pressões de órgãos ambientais e da sociedade, por se tratar de uma indústria altamente poluidora. Com esses fatores negativos da borracha sintética, o consumo da natural vem aumentando nos últimos anos (DURÃO, 2008).

Em 2005, a produção mundial de borracha natural foi da ordem de 8,703 milhões de toneladas (peso seco). Apesar de o Brasil ser o berço do gênero Hevea, a produção nacional da borracha natural é relativamente pequena quando comparada com a dos países asiáticos. Em 2005, a Tailândia, Indonésia, Malásia, Índia, Vietnã e China foram responsáveis pela produção de aproximadamente oito milhões de toneladas de borracha natural (peso de matéria seca), enquanto o Brasil produziu apenas 102 mil toneladas (peso seco). O Brasil, que no início do século XX detinha o monopólio da produção mundial, hoje responde por apenas $1,2 \%$ desse mercado, não conseguindo suprir a demanda da indústria consumidora instalada no país. O consumo nacional de borracha natural em 2005 foi de 297.000 toneladas (peso de matéria seca). Assim, o país importa grande parte da borracha natural que consome. As importações brasileiras em 2005 foram de 203.927 toneladas, o equivalente a 269.222 milhões de dólares. O Brasil importou a referida matéria-prima principalmente da Tailândia (45,8\%), Indonésia $(29,8 \%)$ e Malásia $(21,8 \%)$ (FNP, 2007).

Vários fatores contribuíram para o sucesso da produção de borracha natural nos países asiáticos. Entre esses sistemas, o de produção baseado na exploração comercial e não no extrativismo; a inexistência do fungo causador do mal-das-folhas (Microcyclus ulei), que é uma das doenças mais comuns dos seringais, sobretudo na Amazônia; investimentos em pesquisa agrícola; e grande disponibilidade de mão-de-obra naqueles países.
No Brasil, os fatores que prejudicaram o desenvolvimento do cultivo da seringueira foram o sistema de produção extrativista e ausência de subsídio governamental, à extração de borracha na região amazônica. Quase todas as tentativas de cultivo intensivo da seringueira nessa região fracassaram, devido à incidência do fungo Microcyclus ulei. Além disso, tem-se o fato de o seringal entrar em produção a partir do sexto ano. Até atingir esse estágio, o investidor não terá receitas, o que acaba prejudicando a expansão da cultura no país (BEGA, 2004).

A produção brasileira de borracha natural, entretanto, voltou a crescer, quando a seringueira começou a ser cultivada fora da Amazônia, mais especificamente em regiões em que não há o fungo Microcyclus ulei e quando as políticas públicas que sempre foram destinadas exclusivamente à borracha da Amazônia passaram a contemplar, igualmente, as iniciativas de cultivo em outras regiões, nas décadas de 1970 e 1980. Vale ressaltar que, atualmente, aspectos desvinculados da extração do látex estão impulsionando a heveicultura no Brasil, como: o fato de a seringueira proteger o solo e os mananciais; fixar carbono e, desse modo, contribuir para a redução dos gases de efeito-estufa; e sua madeira poder ser explorada comercialmente. Além disso, outras culturas (cacau, café e leguminosas) podem ser plantadas intercaladas com a seringueira, resultando em renda extra para o produtor (BORRACHA NATURAL, 2007).

Em 2004, a Região Sudeste respondeu por 60,9\% da produção nacional de borracha (látex coagulado), seguida pelas Regiões Centro-Oeste $(21,4 \%)$, Nordeste $(14,6 \%)$, Norte $(2,6 \%)$ e Sul $(0,5 \%)$ (FNP, 2007). Nessas regiões há mão-de-obra especializada; maior volume de capital para investimento em tecnologia; concentração da maioria das indústrias consumidoras de borracha natural, reduzindo os custos logísticos com o transporte da matéria-prima; e clima adequado para o cultivo da seringueira (BORRACHA NATURAL, 2007).

Apesar dos desafios da heveicultura no Brasil, ela está se estabelecendo como atividade lucrativa (NISH et al., 2005; COTTA et al., 2006; SOARES et al., 2006).

A auto-suficiência parcial ou total no suprimento de borracha natural no Brasil e a redução das importações teriam como resultados prováveis a geração de emprego, renda, impostos, redução das pressões sobre o balanço de pagamentos e sobre o meio ambiente etc. 
Até o momento, apenas o estudo de Mera (1977) analisou a demanda brasileira de importação de borracha natural. As estimativas obtidas com análises desta natureza permitem o desenvolvimento de inferências para políticas de importação, controle de estoques e desenvolvimento do setor no país. Assim, torna-se relevante atualizar pesquisas nessa área.

Os principais objetivos deste trabalho foram especificar e estimar a demanda brasileira de importação de borracha natural, no período de 1964 a 2005, bem como analisar o comportamento das importações brasileiras do produto em relação às variações do preço de importação e outras variáveis no curto e longo prazos.

\section{MATERIAL E MÉTODOS}

\subsection{Referencial Teórico}

Tomou-se como referência a teoria da demanda e da demanda de importação, para analisar a demanda brasileira de importação da borracha natural.

Segundo Passos e Nogami (2005) e Bilas (1993), a quantidade demandada $\left(\mathrm{Q}^{\mathrm{D}}\right)$ de um bem ou serviço é função de seu preço $(\mathrm{P})$, do preço de um bem complementar $\left(\mathrm{P}_{\mathrm{C}}\right)$, do preço de um bem substituto $\left(\mathrm{P}_{\mathrm{S}}\right)$, da renda dos consumidores $(\mathrm{Y})$, população (POP), gostos e preferências do consumidor $(\mathrm{G})$ etc. (equação 1 ).

$$
Q^{D}=f\left(P, P_{c}, P_{s}, Y, P O P, G\right)
$$

De acordo com a teoria do consumidor e a classificação de Hicks, a quantidade demandada reage negativamente ao aumento no preço do produto e no preço do bem complementar e positivamente ao incremento do preço do bem substituto e da população. Com relação ao aumento na renda dos consumidores, a quantidade demandada reage positivamente se o bem for normal e, negativamente, se for inferior. As mudanças nos gostos e preferências dos consumidores podem aumentar ou diminuir a quantidade demandada de determinado bem. Ressalta-se que variações nos preços do produto específico provocam deslocamentos ao longo da curva de demanda. Já as mudanças nos preços do bem complementar, no preço do bem substituto, na população, nos gostos e preferências dos consumidores e na renda deslocam a curva de demanda.

Com relação à quantidade importada $\left(Q^{I}\right)$ de determinado produto por um país, pode-se expressála como a diferença entre o consumo total $\left(\mathrm{Q}^{\mathrm{D}}\right)$ e a sua produção interna $\left(\mathrm{Q}_{\mathrm{PI}}\right)$ (equação 2) (KRUGMAN e OBSTFELD, 2005).

$$
Q^{I}=Q^{D}-Q_{P I}
$$

Desse modo, pode-se dizer que a demanda por importação $\left(Q^{I}\right)$ é função do preço de importação do produto $\left(\mathrm{P}_{\mathrm{I}}\right)$, da quantidade produzida internamente $\left(\mathrm{Q}_{\mathrm{PI}}\right)$, do preço de um bem complementar $\left(\mathrm{P}_{\mathrm{C}}\right)$, do preço de um bem substituto $\left(\mathrm{P}_{\mathrm{S}}\right)$ e da renda dos consumidores $(\mathrm{Y})$, da população (POP), dos gostos e preferências do consumidor (G), da taxa de câmbio (TC) etc. (equação 3).

$$
Q^{I}=f\left(P_{l}, P_{c}, P_{s}, Y, P O P, G, T C\right)
$$

\subsection{Referencial Analítico}

Inicialmente, foi calculada a taxa geométrica de crescimento (TGC) da produção brasileira de borracha natural e do consumo, importação e preço de importação, por meio de regressão linear de tendência, conforme a equação 4 .

$$
Y=a \cdot b \cdot T
$$

em que $\mathrm{Y}=$ variável dependente; $\mathrm{T}=$ tempo; e a e b = parâmetros a serem estimados.

Aplicando a forma logarítmica, tem-se (equação 5):

$$
\log Y=\log a+T \log b
$$

Desse modo, a TGC é obtida pela equação 6

$$
T G C=(\text { Anti }-\log b-1) \times 100
$$

Para atingir os objetivos deste trabalho, foi proposto um modelo econométrico composto pela equação de demanda de importação ajustada pelo método Mínimos Quadrados Ordinários (MQO), pois as variáveis explicativas do modelo são todas predeterminadas.

A adoção da suposição de exogeneidade dos preços na equação de demanda de importações parece ser razoável, uma vez que o Brasil é tomador de preço no mercado internacional. A demanda de importação de borracha natural pelo país constitui parcela reduzida da oferta mundial. Nessa situação, a curva de oferta mundial deverá ser perfeitamente preço-elástica, de modo que os deslocamentos na demanda de importação provoquem incrementos somente na quantidade importada e não nos preços. Portanto, o método MQO parece ser o mais apropriado para a estimação da equação (PEREIRA, 1989; SILVA et al. 1997, 1998).

R. Árvore, Viçosa-MG, v.32, n.6, p.1133-1142, 2008 
Então, adotando o método MQO e a forma log$\log$, tem-se:

$$
\begin{aligned}
& \operatorname{Ln}\left(Q^{I}\right)_{t}=\beta_{1}+\beta_{2} \operatorname{Ln}(P I)_{t}+\beta_{3} \operatorname{Ln}(P I B)_{t}+\beta_{4} \operatorname{Ln}(1 \\
& !(T C)_{t}+\beta_{5} \operatorname{Ln}(T J)_{t}+\beta_{6} \operatorname{Ln}(Q P I)_{t}+\beta_{7} T_{t}+\mu_{t}
\end{aligned}
$$

em que $Q_{t}^{I}=$ quantidade importada de borracha natural, em quilograma; $P I_{t}=$ preço de importação da borracha natural, em US\$FOB, que corresponde ao quociente do valor importado pela respectiva quantidade importada; $P I B_{t}=$ produto interno bruto per capita, em US\$/pessoa; $T C_{t}=$ taxa de câmbio, em moeda nacional por dólar, na forma de índice; $T J_{t}=$ taxa de juros "overnight", em \% ao mês; $Q P I_{t}=$ quantidade produzida internamente de borracha natural, em tonelada de borracha seca; $T_{t}=$ tendência $; \mu_{t}=$ termo estocástico; $L n=$ base do $\log$ aritmo neperiano; e $\beta_{1}, \beta_{2}, \beta_{3}, \beta_{4}, \beta_{5}, \beta_{6}, \beta_{7}$, = parâmetros a serem estimados.

A expectativa é de que $\beta_{2}, \beta_{4}, \beta_{5}, \beta_{6},\left\langle 0\right.$ e $\beta_{3}>$ 0 . O sinal de $\beta_{7}$, pode ser maior ou menor que zero. Devido à especificação logarítmica, as elasticidades com relação ao preço de importação e às demais variáveis são dadas diretamente por $\beta_{i}$.

\section{Descrição das variáveis utilizadas}

- Preço das importações: o preço de importação da borracha natural é uma variável exógena do modelo. Espera-se que aumento no preço de importação da borracha natural promova redução na quantidade importada do produto, em virtude dos efeitos de renda real e de substituição.

O conhecimento da elasticidade-preço da demanda de importação é útil na avaliação do efeito de preço sobre quantidade importada, bem como na avaliação de políticas de controle ou incentivo de importação (PEREIRA, 1989).

- Produto interno Bruto per capita (PIB per capita): O PIB per capita do Brasil (PIB do Brasil dividido pela população do país) foi utilizado como indicador de renda. Tomando como base dados anuais do período de 1964 a 2005 do Instituto Brasileiro de Geografia e Estatística (IBGE, 2008) sobre população brasileira, bem como dados da Fundação Getúlio Vargas (FGV, 2006) sobre PIB do Brasil, verificou-se que a população e o PIB do Brasil cresceram a uma taxa média anual de $2,05 \%$ e $6,32 \%$, respectivamente. Com isso, o PIB per capita ou a renda por habitante no país cresceu em média 8,37\% ao ano, no referido período. Ressaltase que o PIB per capita contém o efeito da renda e da população. Então, era de se esperar que o crescimento do PIB per capita fosse maior que o crescimento da população. Era esperado, também, que o PIB e a população não crescessem na mesma proporção, pois não são influenciados pelas mesmas variáveis.

Espera-se que, aumentando a renda dos consumidores brasileiros, aumente a demanda de importação da borracha natural, pois se acredita que com o incremento da renda os consumidores irão demandar mais produtos das indústrias que utilizam a matériaprima de produção da borracha natural. Isso poderá estimular a produção dessas indústrias e, conseqüentemente, elevar o consumo da borracha natural. Como a produção nacional de borracha natural não é suficiente para atender à demanda das indústrias instaladas no país, a expectativa é de que as importações nacionais da referida matéria-prima aumentarão.

O conhecimento da elasticidade-renda é útil na avaliação do impacto da expansão (ou restrição) da renda sobre as importações de borracha natural.

- Taxa de câmbio: a taxa nominal de câmbio tem efeito negativo sobre a demanda de importação do produto, ou seja, uma desvalorização da moeda nacional em relação à moeda estrangeira (Dólar) torna as importações de borracha natural menos atrativas. Conseqüentemente, diminui a demanda brasileira de importação de borracha natural.

- Taxa de juros: teoricamente, quanto maior a taxa de juros, menor o consumo de bens duráveis. Assim, espera-se que acréscimo na taxa de juros diminua a demanda brasileira de importação de borracha natural.

- Quantidade produzida internamente de borracha natural: espera-se que aumento da quantidade produzida de borracha natural no país reduza a demanda brasileira de importação desse produto, visto que a borracha natural nacional e a importada são similares.

- Tendência: o conhecimento da elasticidade de tendência da demanda de importação é útil na avaliação do efeito de mudanças tecnológicas e de acumulação de capital na indústria nacional de borracha natural sobre a importação do produto.

- Os preços dos bens substitutos e complementares não foram considerados na análise, pois para a borracha 
natural não se têm substituto perfeito e produto complementar bem definido (GAMEIRO e GAMEIRO, 2002).

\section{Testes estatísticos}

Para testar a significância da regressão obtida pelo método Mínimos Quadrados Ordinários (MQO), utilizouse o teste $F$, enquanto o grau de ajustamento da regressão foi avaliado por meio do coeficiente de determinação $\left(\mathrm{R}^{2}\right)$.

A significância dos coeficientes individualmente foi verificada por meio do teste "t," de Student. As variáveis cujos coeficientes não foram significativos, ou cujos sinais não estavam coerentes com a teoria econômica, foram excluídas do modelo.

A existência de heterocedasticidade foi avaliada pelo teste de White. Caso seja observado heterocedasticidade, a variância de cada terno estocástico não é constante.

Para verificar a existência de correlação serial nos resíduos, utilizou-se a estatística h, de Durbin, pois em equações que contêm valores defasados de variável endógena não é apropriado o teste d, de Durbin-Watson. Mais precisamente, buscou-se verificar, por meio da estatística h, de Durbin, se o desvio-padrão dos coeficientes estimados são verdadeiros.

Utilizaram-se as regressões auxiliares e a regra de Klein para avaliar o problema da multicolinearidade, ou seja, para verificar se os coeficientes foram estimados com grande precisão ou exatidão.

A análise de normalidade dos resíduos foi feita por meio do teste de Jarque-Bera. Assim, se for constatado que os resíduos seguem distribuição normal, isso significa que o método utilizado para ajustar a regressão (MQO) é o correto.

\section{Modelo de Ajustamento Parcial (NERLOVE)}

Nesse estudo, empregaram-se modelos com defasagem distribuída, segundo a formulação original de Nerlove, para examinar a hipótese de existência de um mecanismo de ajustamento não-instantâneo na importação brasileira de borracha natural. Desse modo, permite-se a diferenciação entre as elasticidades no curto e longo prazos.
Tomando como base Gujarati (2000) e Silva et al. (1997), o modelo de Nerlove pressupõe o seguinte (equação 7):

$$
Y^{*}=\beta_{0}+\beta_{1} X_{t}+\mu_{t}
$$

em que: $\mathrm{Y}^{*}=$ importação desejada de $\mathrm{Y}$, no ano $\mathrm{t}$.

Como o nível desejado não é diretamente observável, Nerlove postulou a hipótese de ajustamento parcial (equação 8).

$$
Y_{t}-Y_{t-1}=\delta\left(Y_{t}^{*}-Y_{t-1}\right) \text { ou } Y_{t}=\delta Y^{*}+(1-\delta) Y_{t-1}
$$

em que: $Y_{t}^{*}-Y_{t-1}=$ mudança desejada em Y; $Y_{t}-Y_{t-1}=$ mudança atual em Y; e $\delta=$ elasticidade de ajustamento.

Com a substituição de 7 em 8, tem-se (equação 9):

$$
Y_{t}=\delta \beta_{0}+\delta \beta_{1} X_{t}+(1-\delta) Y_{t-1}+\delta \mu_{t}
$$

Esse modelo é chamado de modelo de ajustamento parcial. As equações 7 e 8 são denominadas equação de longo prazo e curto prazos, respectivamente.

A relação estimada seria (equação 10):

$$
\hat{Y}=\hat{a}_{0}+\hat{a}_{1} X_{t}+\hat{a}_{2} Y_{t-1}
$$

Com as variáveis na forma log-log, pode-se dizer que elasticidade de curto prazo é $\hat{a}_{1}=\delta \beta_{1}$; elasticidade de longo prazo $=\hat{\beta}_{1}$; coeficiente de ajustamento $=\delta$; e tempo de ajustamento é $(1-\delta)^{t}=1-\theta \therefore t=\frac{\log (1-\theta)}{\log (1-\delta)}$, em que $\theta=$ proporção da demanda de longo prazo.

\subsection{Fontes de Dados}

Os dados utilizados são provenientes de séries temporais anuais, abrangendo o período de 1964 a 2005. Não se trabalhou com um período maior porque alguns dados não estavam disponíveis e por entender que o período abrangido é representativo e capta a evolução do setor de borracha natural. As séries foram construídas conforme indicado a seguir.

A quantidade importada e o valor das importações brasileiras de borracha natural foram obtidos no banco de dados Aliceweb e no Anuário Estatístico da Carteira de Comércio Exterior - CACEX do Banco do Brasil. A quantidade importada de borracha natural pelo Brasil está em tonelada de borracha seca e o valor das exportações, em US\$ FOB. Dividindo a quantidade

R. Árvore, Viçosa-MG, v.32, n.6, p.1133-1142, 2008 
importada pelo valor das importações, obteve-se o preço de importação da borracha natural, em US\$ FOB.

O PIB per capita do Brasil, como dito anteriormente, refere-se ao PIB nacional dividido pela população brasileira e foi utilizado com indicador de renda. Esse PIB foi obtido na Conjuntura Econômica da FGV (FGV, 2006) e a população brasileira, no IBGE (IBGE, 2008). O PIB per capita do Brasil está em US\$/pessoa.

A produção de borracha natural no país, em tonelada de borracha seca, foi obtida no Anuário EstatísticoMercado Estrangeiro da Superintendência da Borracha (Sudhevea) e no AGRIANUAL.

Os dados sobre taxa de câmbio (Real/US\$), na forma de índice, e taxa de juros, correspondente à taxa de empréstimos financeiros, "overnight" (\% a.m.), foram obtidos no banco de dados do Instituto de Pesquisa Econômica Aplicada (IPEA).

\section{RESULTADOS E DISCUSSÃO}

\subsection{Tendências do Mercado de Borracha Natural}

No Quadro 1, apresenta-se a TGC de quatro variáveis (produção, consumo, importação e preço de importação da borracha natural), que caracterizam a evolução do mercado nacional de borracha natural, no período de 1964 a 2005. O comportamento dessas variáveis pode ser verificado na Figura 1.

Observando o Quadro 1 e a Figura 1, notou-se que, apesar de a produção nacional da borracha natural ainda ser pequena quando comparada com a dos países asiáticos, ela cresce substancialmente a cada ano, segundo uma taxa geométrica média de 3,6\% ao ano. Verificou-se que ocorreu grande expansão da produção nacional de borracha natural em meados da década de 1990, isso devido à modernização da indústria de beneficiamento da borracha no país (BORRACHA NATURAL, 2007).
O consumo de borracha natural no Brasil cresceu a uma taxa de 5,4\% ao ano. Assim, a discrepância entre as taxas de crescimento da produção doméstica e consumo do consumo total foi da ordem de $1,8505 \%$.

Como a produção nacional foi sempre menor que o consumo, as importações brasileiras de borracha natural cresceram à taxa de 7,6\% ao ano, no período considerado nesta análise (1964-2005).
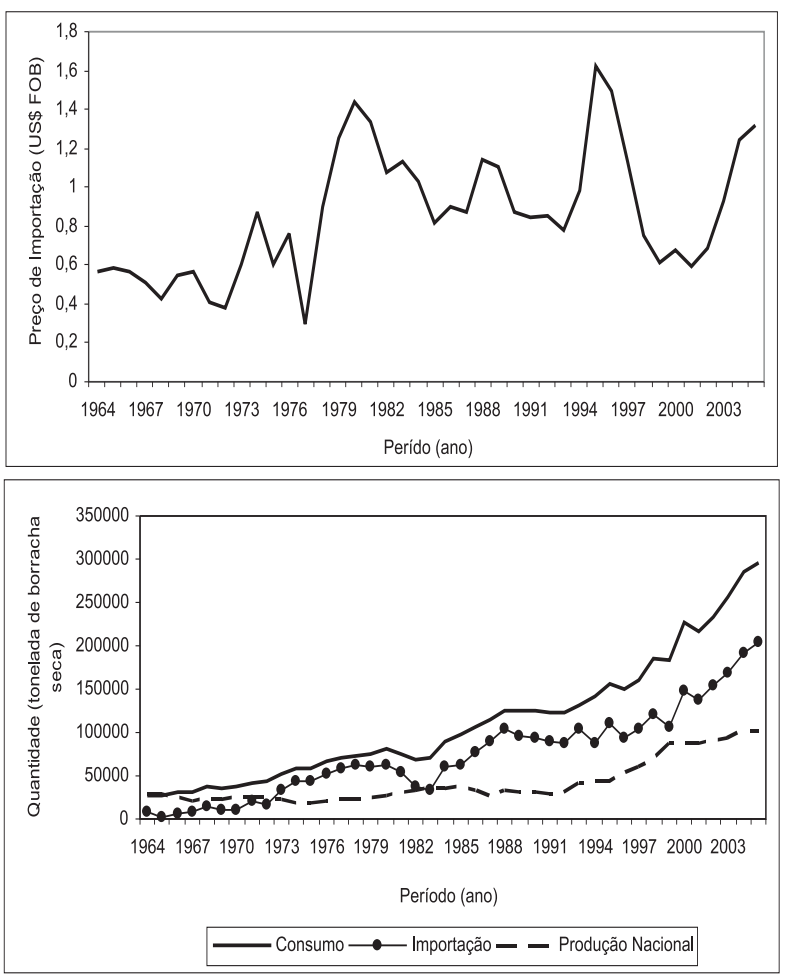

Fonte: Aliceweb (2006); Sudhevea (vários anos), Banco do Brasil (vários anos); Agrianual (vários anos).

Figura 1 - Preço de importação, consumo, importação e produção de borracha natural no Brasil, 1964 a 2005.

Figure 1 -Import price, natural rubber consumption, importation and production in Brazil, 1964 to 2005.

Quadro 1 - Taxa geométrica de crescimento (TGC), no período de 1964 a 2005

Table 1 - Growth geometric rate from 1964 to 2005

\begin{tabular}{llc}
\hline \multicolumn{1}{c}{ Variável } & Unidade & TGC $(\%$ ao ano) \\
\hline Quantidade produzida Intenamente (QPI) & Tonelada de borracha seca & $3,6165 *$ \\
Consumo (CONS) & Tonelada de borracha seca & $5,4670 *$ \\
Quantidade Importada (QI) & Tonelada de borracha seca & $7,6282 *$ \\
Preço de Importação (PI) & US\$FOB & $1,6667 *$ \\
\hline
\end{tabular}

Fonte: Resultados da pesquisa. * significativo a $1 \%$. 
O preenchimento do déficit entre produção e consumo por meio de importação a preços que também cresceram a uma taxa geométrica média de $1,6 \%$ ao ano onerou significativamente a balança comercial do país e o balanço de pagamentos. As constantes desvalorizações cambiais dos países asiáticos, como dito anteriormente, são os maiores produtores mundiais de borracha natural, prejudicam a competitividade da produção nacional. Isso pode explicar a taxa geométrica de crescimento relativamente baixa dos preços de importação da borracha natural.

\subsection{Estimativas da Demanda Brasileira de Importação de Borracha Natural}

São apresentados, a seguir, os resultados das estimativas da equação de demanda brasileira de importação de borracha natural, no período de 1964 a 2005.

As variáveis que se mostraram relevantes para explicar as variações na demanda brasileira de importação de borracha natural foram: preço de importação da borracha natural (PI), PIB per capita (PIB), taxa de câmbio (TC), taxa de juros (TJ), quantidade de borracha natural produzida no país (QPI) e tendência $(\mathrm{T})$.

Vale ressaltar, entretanto, que outras variáveis também podem explicar a demanda brasileira de importação de borracha natural, a exemplo do consumo de pneus e do preço do petróleo, entre outras.

O melhor ajustamento foi obtido utilizando o modelo na forma logarítmica.

No Quadro 2 são apresentadas as estimativas da equação de demanda brasileira de importação de borracha natural com defasagem distribuída, utilizando-se o método Mínimos Quadrados Ordinários (MQO).
O coeficiente de determinação $\mathrm{R}^{2}$ mostrou que $96,01 \%$ das variações ocorridas na demanda brasileira de importação de borracha natural foram explicadas pelas variáveis predeterminadas no modelo.

O coeficiente das variáveis explicativas, taxa de câmbio (TC), taxa de juros (TJ), quantidade de borracha natural produzida no país (QPI) e tendência (T) foram significativos em nível de $1 \%$ de probabilidade. Já o coeficiente da variável explicativa defasada foi significativo em nível de $4 \%$ de probabilidade, enquanto o do preço de importação da borracha natural (PI) e do PIB per capita (PIB) foi significativo em níveis de $9 \%$ e $34 \%$ de probabilidade, respectivamente.

Todos os sinais dos coeficientes de regressão parcial dessas variáveis são coerentes com a teoria da demanda de importação e, ou, com o conhecimento empírico.

O coeficiente de regressão parcial da variável defasada indicadora de importação retardada de borracha natural $\left(\mathrm{Q}_{\mathrm{t}-1}^{\mathrm{I}}\right)$ apresenta sinal positivo, ou seja, evidencia que os importadores não se ajustam instantaneamente aos estímulos de preço.

O sinal positivo das variáveis PIB e T indicou relação direta entre essas variáveis e a demanda brasileira de importação de borracha natural. Já o sinal negativo dos coeficientes das variáveis PI, TC, TJ e QPI revelou relação inversa entre essas variáveis e a demanda brasileira de importação de borracha natural.

O teste h, de Durbin, aplicado à equação de demanda de importação, para avaliar a existência de correlação serial nos resíduos, sugeriu ausência de correlação serial nos resíduos.

Quadro 2 - Estimativas da equação de demanda brasileira de importação de borracha natural, 1964 a 2005 Table 2 - Brazilian demand estimates for natural rubber importation, 1964 to 2005

\begin{tabular}{|c|c|c|c|c|}
\hline Variável explicativa & Descrição & Coeficiente estimado & Erro-padrão & Teste $\mathrm{t}$ \\
\hline Constante & & 19,54632 & 3,723333 & 5,249683 \\
\hline $\operatorname{Ln} Q_{t-1}^{I}$ & Import. da borracha natural, ano $\mathrm{t}_{-1}$ & $0,223547 * *$ & 0,109225 & 2,046665 \\
\hline Ln PI & Preço de import. da borracha natural & $-0,215711 * * *$ & 0,123882 & $-1,741269$ \\
\hline Ln PIB & PIB per capita & $0,180546 * * * *$ & 0,180176 & 1,002054 \\
\hline Ln TC & Taxa de câmbio & $-0,043828 *$ & 0,011174 & $-3,922461$ \\
\hline Ln TJ & Taxa de juros & $-0,123483 *$ & 0,049301 & $-2,504699$ \\
\hline Ln QPI & Quant. de borracha natural produzida no país & $-1,037943 *$ & 0,277860 & $-3,735493$ \\
\hline $\mathrm{T}$ & Tendência & $0,132332 *$ & 0,023451 & 5,642896 \\
\hline $\mathrm{R}^{2}=0,960140$ & $\mathrm{~h}=-1,6929(\mathrm{sc})$ & & \multicolumn{2}{|c|}{$\mathrm{F}=116,9967 *$} \\
\hline
\end{tabular}


A estatística F significativa em nível de $1 \%$ de probabilidade evidenciou que as variáveis explicativas são, conjuntamente, significativas para explicar a demanda brasileira de importação de borracha natural.

Segundo o critério de Klein, parecem ser de pouca influência os efeitos da multicolinearidade nas estimativas dos parâmetros das variáveis explicativas, pois o valor de $\mathrm{R}^{2}$ obtido da equação de demanda de importação foi maior que o $\mathrm{R}^{2}$ obtido das regressões auxiliares.

A partir da equação de demanda de importação em curto prazo, pode ser obtida a equação de demanda de importação em longo prazo:

$$
\begin{aligned}
& \operatorname{Ln}_{t}=251,7386-0,27782 \operatorname{LnPI}+0,232527 \mathrm{Ln} \\
& \operatorname{LnPIB}-0,05645 \text { LnTC-0,15903 LnTJ-1,33678 } \\
& \operatorname{Ln} Q P I+0,170431 T
\end{aligned}
$$

Como as estimativas foram feitas a partir de um modelo logarítmico, os parâmetros podem ser interpretados diretamente como as estimativas das elasticidades de demanda de importação. Assim, as elasticidades-preço da demanda brasileira de importação de borracha natural foram iguais a $-0,21$ e $-0,27$, no curto e longo prazos, respectivamente, indicando que aumento de $10 \%$ no preço de importação da borracha natural ocasionaria redução na quantidade importada do referido produto, de $2,1 \%$ no curto prazo e de $2,7 \%$ no longo prazo, ceteris paribus, o que indica que a demanda brasileira de importação de borracha natural é inelástica com relação ao preço de importação e pouco sensível às variações nele no curto e longo prazos.

Soependi (1993), considerando o período de 1970 a 1990, constatou que a elasticidade-preço da demanda de importação mundial por borracha natural da Indonésia é de $-0,18$, ou seja, é inelástica com relação ao preço de importação.

Já Mera (1977), utilizando dados que englobam o período de 1920 a 1972, concluiu que a elasticidadespreço da demanda brasileira de importação de borracha natural é de $-1,11$, indicando que a importação brasileira de borracha natural é sensível às variações de preço de importação do produto. Porém, este estudo engloba um período muito diferente do considerado nesta pesquisa e em Soependi (1993).

O valor relativamente baixo da elasticidade-preço da demanda de importação de borracha natural encontrado neste trabalho e no de Soependi (1993) pode estar relacionado ao aumento da importância relativa da borracha natural em relação à sintética desde a década de 1980, conforme observaram Gameiro e Gameiro (2002). Pelo fato de se tratar de matéria-prima essencial na indústria de pneumáticos e derivados e na indústria de artefatos em geral, bem como possuir características intrínsecas de tensão, solidez e resistência, o uso da borracha natural é indispensável na indústria automobilística, limitando o grau de substituição pela borracha sintética (MERA, 1977).

A elasticidade-renda da demanda brasileira de importação de borracha natural foi de 0,18 e 0,23 no curto e longo prazos, respectivamente, indicando que a borracha natural é um bem normal e aumento de $10 \%$ na renda (representada pelo PIB per capita) causaria incremento na demanda de importação do produto de $1,8 \%$ e $2,3 \%$, no curto e longo prazos, respectivamente, ceteris paribus. Conclui-se que a demanda brasileira de importação de borracha natural é renda-inelástica, no curto e longo prazos, ou seja, os aumentos na renda nacional promovem incrementos menos que proporcionais na quantidade demandada de importação deste produto pelo Brasil.

Com relação à taxa de câmbio, pode-se dizer que, quando ocorre desvalorização de $10 \%$ da moeda nacional em relação ao dólar, a demanda brasileira de importação de borracha natural diminui $0,4 \%$ e $0,5 \%$ no curto e longo prazos, ceteris paribus.

Aumento de $10 \%$ na taxa de juros provoca, no entanto, redução na demanda brasileira de importação de borracha natural, de $1,2 \%$ e $1,5 \%$ no curto e longo prazos, ceteris paribus.

Já aumento de $10 \%$ na quantidade de borracha natural produzida internamente provoca decréscimo na demanda brasileira de importação de borracha natural de $10,3 \%$ e de $13,6 \%$ no curto e longo prazos, ceteris paribus. Isso mostra que a demanda brasileira de importação de borracha natural é sensível às variações na quantidade de borracha natural produzida internamente ou que o mercado interno tem absorvido bem a produção nacional de borracha natural.

O sinal positivo da variável tendência indica que a demanda brasileira de importação de borracha natural, no período de 1964 a 2005, estaria se deslocando para a direita, a uma taxa média de $13,23 \%$ e 17,04\% ao ano, no curto e longo prazos, respectivamente. 
Nesse contexto, conclui-se que, se o objetivo for redução das importações brasileiras de borracha natural, a elasticidade-preço da demanda brasileira de importação do produto indica que uma política de tributação (tarifas) das importações não seria tão efetiva. A utilização de cotas talvez seja necessária.

A elasticidade da taxa de câmbio e da taxa de juros também sugere pouca efetividade de políticas de desvalorização cambial e de aumento da taxa de juros, respectivamente, visando à redução das importações.

Políticas governamentais voltadas para o aumento da produção nacional de borracha natural, como investimento em pesquisa para aumentar a produtividade da seringueira, parecem contribuir para a redução das importações brasileiras do produto.

O coeficiente de ajustamento estimado de 0,77 indica que cerca de $77 \%$ do ajustamento de equilíbrio em longo prazo é realizado no decorrer de um ano, ao passo que são necessários 2,6 anos para que se verifiquem $98 \%$ do ajuste pleno, isto é, para que a demanda de importação atual de borracha natural atinja $98 \%$ da demanda desejada, ceteris paribus. O coeficiente de elasticidade de ajustamento estimado evidencia que os agentes envolvidos com a borracha natural não respondem, no período de um ano, aos incentivos econômicos a eles concedidos, o que pode ser explicado pela falta de infra-estrutura e limitação de capital, entre outros fatores relacionados às indústrias de borracha natural do país.

\section{CONCLUSÕES}

As informações deste trabalho permitiram as seguintes conclusões:

- As variáveis predeterminadas no modelo têm bom poder de explicação das variações na demanda brasileira de importação de borracha natural.

- A demanda brasileira de importação de borracha natural é inelástica com relação ao preço de importação do produto e com relação à renda de curto e longo prazos e é mais sensível a variações na quantidade de borracha natural produzida internamente.

- As autoridades brasileiras precisam investir no fomento da produção nacional como meio de reduzir a dependência externa no suprimento da referida matéria-prima.
- Políticas que aumentem os preços de importação são ineficazes para reduzir as quantidades importadas de borracha. Por conseguinte, barreiras não-tarifárias, como cotas de importação, constituem-se em medidas apropriadas se o objetivo for impedir que haja competição desleal das importações com a produção nacional.

Apesar de as variáveis predeterminadas no modelo terem bom poder de explicação das variações na demanda brasileira de importação de borracha natural, recomendase, em outros trabalhos de pesquisa, estimar a demanda brasileira de importação de borracha natural, incluindo outras variáveis no modelo, a exemplo do preço do petróleo e do consumo de pneus, entre outras, com o intuito de verificar o seu efeito sobre a demanda de importação de borracha natural.

\section{REFERÊNCIAS}

Sistema de análise das informações de comércio exterior - ALICEWEB. Estatísticas. Disponível em: <http://aliceweb.desenvolvimento.gov.br/ default.asp> Acesso em: 15/12/2006.

\section{BANCO DO BRASIL. Anuário Estatístico da Carteira de Comércio Exterior - CACEX. (vários anos).}

BEGA, R. M. Heveicultura: alternativa para o pequeno proprietário rural no noroeste paulista. 2004. 88 f. Monografia (Especialização em Gestão do Agronegócio) - Universidade Federal de Viçosa, Viçosa, MG, 2004.

BILAS, R. A. Teoria microeconômica. 12.ed. Rio de Janeiro: Forense Universitária, 1993. 404p.

\section{BORRACHA NATURAL BRASILEIRA.}

Borracha natural. Disponível em: <http:// www.borrachanatural.agr.br/borrachanatural.php $>$. Acesso em: 12 de jan. de 2007.

COTTA, M. K. et al. Análise econômica do consórcio seringueira-cacau para geração de certificados de emissões reduzidas. Revista Árvore, v.30, n.6, p.969-979, 2006.

DURÃO, E. Demanda de Borracha. 2008. Disponível em: <http://www.heveabrasil.com/ ?page=futuro_da_seringueira.asp $>$. Acesso em: 20 de maio de 2008.

R. Árvore, Viçosa-MG, v.32, n.6, p.1133-1142, 2008 
FNP. Consultoria e Comércio. AGRIANUAL. Anuário estatístico da agricultura brasileira. São Paulo: FNP Consultoria e Comércio, (vários anos).

FUNDAÇÃO GETÚLIO VARGAS - FGV. Conjuntura Estatística - Contas Nacionais. Conjuntura Econômica, v. 60, n.11, p.19, 2006.

GAMEIRO, A. H.; GAMEIRO, M. B. P. Relação entre preço e consumo das borrachas natural e sintética no mundo, período 1981 a 2000. Informações Econômicas, v.32, n.11, p.7-15, 2002.

GUJARATI, D. N. Econometria Básica. 3.ed. São Paulo: Makron Books, 2000. 846p.

INSTITUTO BRASILEIRO DE GEOGRAFIA E ESTATÍSTICA - IBGE. 2008. Disponível em: <http://www.ibge.gov.br>. Acesso em: 19 de maio de 2008.

\section{INSTITUTO DE PESQUISA ECONÔMICA} APLICADA - IPEA. Ipeadata. Disponível em: <http://www.ipeadata.gov.br>. Acesso em: 18 de dez. 2006.

KRUGMAN, P. R.; OBSTFELD, M. Economia internacional: teoria e política. 6.ed. São Paulo: Pearson Addison Wesley, 2005. 558p.

MERA, R. D. M. Análise econométrica da estrutura de mercado mundial de borracha natural. 1977. 73f. Dissertação (Mestrado em Economia Rural) - Universidade Federal de Viçosa, MG, 1977.

NISHI, M. H. et al. Influência dos créditos de carbono na viabilidade financeira de três projetos florestais. Revista Árvore, v.29, n.2, p.263-270, 2005.

R. Árvore, Viçosa-MG, v.32, n.6, p.1133-1142, 2008
PASSOS, C. R. M.; NOGAMI, O. Princípios de economia. 5.ed. São Paulo: Pioneira Thomson Learning, 2005. 658p.

PEREIRA, L. C. L. A demanda de importação de insumos agrícolas: o caso de fertilizantes. 1989. 46f. Dissertação (Mestrado em Economia Rural) - Universidade Federal de Viçosa, Viçosa, 1989.

PEREIRA, J. P. et al. Cadeia produtiva da borracha natural: análise diagnóstica e demandas atuais no Paraná. Londrina: IAPAR, 2000. 85p.

SANTOS, G. R.; MOTHÉ, C. G. Prospecção e perspectivas da borracha natural, Hevea brasiliensis. Revista Analytica, n.26, p.32-41, 2007.

SILVA, M. L. et al. Análise econométrica do mercado brasilerio de celulose. Nova Economia, v.7, n.2, p.109-129, 1997.

SILVA, M. L. et al. Análise do mercado brasileiro de papel e papelão. Estatística Econômica, v.28, n.1, p.77-97, 1998.

SOARES, N. S. et al. Aspectos técnicos e sociais da heveicultura e viabilidade econômica. In: ALVARENGA, A. P. et al. Seringueira: aspectos econômicos sociais e perspectiva para o seu fortalecimento. Viçosa, MG: 2006. p.141-163.

SOEPENDI, I. Y. Indonesian natural rubber: an econometric analysis of its export supply and foreign import demand. 1993. Disponível em: <http:// www.aec.msu.edu/theses/abstract.cfm?RecordID=1087>. Acesso em: 10 de jan. de 2007.

SUPERINTENDÊNCIA DA BORRACHA SUDHEVEA. Anuário Estatístico Mercado Estrangeiro. Ministério da Indústria e Comércio, (vários anos). 